\title{
Age and the development of trust and reciprocity ${ }^{*}$
}

\author{
Matthias Sutter ${ }^{\S, \dagger, \#}$ and Martin G. Kocher $^{\dagger}$ \\ $\S$ Max Planck Institute for Research into Economic Systems Jena \\ ${ }^{\dagger}$ University of Innsbruck
}

This version: 15 December 2003

\begin{abstract}
We examine the degree of trust and reciprocity in an experimental trust game with 662 participants from six different age groups, ranging from 8 year old primary school children to retired persons in their late sixties. Although both trust and reciprocity have been identified as fundamental pillars for smooth and efficient economic interactions, economic research has devoted surprisingly little attention to their development with age. Our results provide clear evidence that trust in anonymous partners increases almost linearly from early childhood to early adulthood, but stays constant afterwards. Reciprocity prevails in all age groups, although its degree also seems to increase with age.
\end{abstract}

JEL-classification: $\quad$ C72, C91

Keywords: $\quad$ trust, reciprocity, age, development, experiment

* We would like to thank Simon Gächter, Werner Güth, Hakan Holm, Rupert Sausgruber, Christiane Schwieren, participants at the Second Symposium on Psychology and Economics (2003) at the University of Tilburg and at the European Meeting of the Economic Science Association (2003) in Erfurt as well as seminar participants at the Humboldt-University Berlin and the University Frankfurt/Main for very helpful comments on this paper. Jiro Netzer and Clemens Piekarz provided excellent assistance in conducting the experiments. Financial support from the Center for Experimental Economics at the University of Innsbruck (sponsored by Raiffeisen-Landesbank Tirol) and from the Austrian National Bank (through Jubiläumsfonds-Project 8487) is gratefully acknowledged.

\# Corresponding author: Max Planck Institute for Research into Economic Systems, Strategic Interaction Group, Kahlaische Strasse 10, D-07745 Jena, Germany, Phone: +49-3641-686-642, Fax: +49-3641-686-623, email: sutter@mpiew-jena.mpg.de 


\section{Introduction}

Trust and reciprocity are fundamental pillars for smooth and efficient interactions when complete contracts are not feasible or available. This is true not only within families, in neighborhoods, or schools, but also in larger public and private organizations, markets, or politics (Alesina and La Ferrara, 2002; Bewley, 1999; Fehr and Falk, 1999; Fehr et al., 1993, 1997; Glaeser et al., 2000). It is obvious that many economic interactions are characterized by an exchange of favors or goods and services, where the quality or quantity of the exchange cannot be enforced strictly. Without mutual trust and the social norm of reciprocal behavior, most of these exchanges would not take place, much to the detriment of the involved parties in particular and of society in general (Knack and Keefer, 1997; Zak and Knack, 2001).

Despite a rapidly increasing general interest of economists in the determinants and economic benefits or consequences of trust and reciprocity, the development or evolution of trust and reciprocity with age has widely been neglected so far. ${ }^{1}$ Given that the evolution of the two concepts bears important relevance for economic interactions, we provide a comprehensive (experimental) study on the development of trust and reciprocity across different age groups.

Specifically, we conducted a controlled experiment with 662 subjects from six different age groups: 8 year old second graders in primary school, 12 year old sixth graders, 16 year old tenth graders in secondary school, students in their early twenties, working professionals in their mid thirties, and retired persons in their late sixties. All subjects participated in identical trust games, which allowed us to assess possible differences in trust and reciprocity contingent on age.

Why should economists care about the development of trust and reciprocity with age? Trust and reciprocity play an important role in many human interactions. A study that allows

\footnotetext{
${ }^{1}$ One prominent exception, Harbaugh et al. (2002b), will be discussed in section 2.
} 
insights into the origins and the development of trust and reciprocity will, obviously, help to explain why trust and reciprocity are so widespread in economic transactions. Consequently, it will lead to a better understanding - and, ultimately, modeling - of economic decision making and behavior of adults. For instance, studying the behavior of older adults, like retired persons who control a considerable part of the wealth of a society, is helpful in examining whether the standard models of economic decision making, which are heavily rooted in (experimental) studies of 20 year old students, are useful in predicting behavior of wealthy, experienced people. ${ }^{2}$

If trust and reciprocity actually develop with age, members of specific age groups will show different behavior in economic interactions. For instance, studying the behavior of children, and especially of adolescents is interesting for economists because the purchasing power of children and adolescents has increased considerably over the past few decades, at least as far as highly developed countries as the U.S. are concerned (McNeal, 1992). Consequently, children are much more often involved in economic transactions than previously, for instance when trading goods on the Internet, where trust is an important prerequisite.

Besides providing insights into the economic behavior of children and adolescents, tracking the development of trust and reciprocity with age may promote a better understanding of adult behavior. In particular, it will answer the question whether the degree of trust and reciprocity shows a systematic pattern depending upon age, like an increase or a decrease with age. If, for instance, trust and reciprocity decrease in the course of human life, society would be well advised to take countermeasures to prevent such a development and to

\footnotetext{
${ }^{2}$ A very recent study by Kovalchik et al. (2004) reports a broad comparative study of decision behavior of elderly (average age 82) and young individuals (aged about 20), showing that the decision behavior of older subjects (in choices over monetary gambles) is very similar to that of students and sometimes even less prone to decision anomalies.
} 
sustain the initially higher levels of trust and reciprocity. If, on the contrary, trust and reciprocity increase with age, economists could provide empirical evidence and tools on how to promote the development of both concepts in early childhood.

In contrast to the usual survey questions on trust, trustworthiness, and reciprocity (see Durlauf, 2002; Glaeser et al., 2002), we prefer to measure trust and trustworthiness in an experimental setting mainly for two reasons. First, decisions have clear monetary consequences and, second, it is much easier to explain a simple game to young children than a set of hypothetical questions that adults are usually asked in those surveys. The experimental trust game that we apply in our experiment has been used in numerous studies to measure trust, trustworthiness, and reciprocity. ${ }^{3}$ In this paper, we apply a slightly modified version of the trust game, which was introduced in the literature by Berg et al. (1995). Player A, the trustor, has an initial endowment $X>0$ and can send an amount $x$ to player B, the trustee, with $0 \leq x \leq X$. Player B receives $3 x$ and can return to player A any amount $y$, with $0 \leq y \leq 3 x$. The final payoff for player A is $X-x+y$, and for player B it is $3 x-y$.

The amount $x$ can be used as a measure for the trustor's trust in an anonymous interaction partner. ${ }^{4}$ In our setting, trust is the willingness to transfer a positive amount $(x>0)$ to the other person in the hope that this person will reciprocate at her own cost. ${ }^{5}$ The return $y$, in

\footnotetext{
${ }^{3}$ For a survey of results see, e.g., Camerer (2003). Some recent related topics addressed in the literature are the influence of gender on trust and reciprocity (Croson and Buchan, 1999; Cox and Deck, 2002) - with no indication of substantial differences between men and women - or differences between individuals and unitary groups as decision makers (Cox, 2002; Bornstein et al., 2003) - with groups showing less trust and being less trustworthy than individuals.

${ }^{4}$ Inequity aversion or other forms of social preferences might, of course, also be relevant for the decision of the trustor. We will discuss the issue of disentangling various possible motives of trustors in section 5.

${ }^{5}$ This comes close to a widespread definition of trust to be the deliberate willingness of a decision maker to be vulnerable to the actions of another decision maker (Mayer et al., 1995; Rousseau et al., 1998).
} 
relation to the received amount $3 x$, is an indicator for a subject's reciprocal behavior. The higher $y$ - for a given $x$ - the greater the degree of reciprocity. ${ }^{6}$

The results of our experiment indicate that trust in anonymous partners, that is strangers, increases almost linearly from primary school children to students, but stays more or less the same in our adult population of students, working professionals, and retired persons. Reciprocity (that means a significantly positive dependence of $y$ on $x$ ) is prevalent in all age groups, but with increasing age, subjects become less self-regarding in their decisions as trustees. This finding implies that trust pays off to a greater extent with older bargaining partners. Retired persons turn out to be most generous in the role of trustee.

The rest of the paper is organized as follows: Section 2 introduces evidence from economics and developmental psychology as well as our hypotheses that are derived from the large body of work in developmental psychology. Section 3 describes our experimental design and procedure in detail. Results are presented in section 4. Section 5 discusses our results and possible future extensions of our work.

\section{Evidence from economics and hypotheses from developmental psychology}

\section{A. Evidence from economics}

Only recently, the influence of age on economic decision making has caught some attention in economics. Basically, there are two strands of literature closely related to our

\footnotetext{
${ }^{6}$ Reciprocity is often defined to imply a(n) (un)friendly reaction to another subject's (un)friendly action (Fehr and Gächter, 2000). Evidently, trust and reciprocity are intimately related as trusting behavior can only be rewarded in the presence of reciprocity and as trust itself may elicit reciprocity.
} 
paper. The first strand examines the economic behavior of children, and the second concentrates on behavioral differences between specific adult age groups.

Harbaugh, Krause, and co-authors are the most prominent contributors to the first strand of literature. ${ }^{7}$ Harbaugh et al. (2002b) present - to the best of our knowledge - the only experimental trust game with children of different age, ranging from 8 year olds to 17 year olds. They do not find any significant influence of age on trustors' or trustees' decisions, which might be a consequence of the applied strategy vector method, as they mention themselves. ${ }^{8}$ In particular, they note that children might have found it very difficult to understand how the strategy vector method protocol is implemented. In addition to possible confusion, the potential lack of salience associated with the strategy vector method might have been more important for children than for adults.

Inspired by the work of Harbaugh et al. (2002b), we extend and modify their approach in three notable dimensions: First of all, due to the possible problems with the strategy vector method mentioned above, we refrain from applying it and elicit only a single, unconditional choice from every participant. Second, we extend their study to cover the full range of the human life cycle by having children, adolescents, students, working professionals, and retired persons participate in our experiment. To the best of our knowledge, we are the first to analyze trust and reciprocity over the whole life span. Third, our experimental study will be

7 Besides studying children behavior in a trust game, Harbaugh, Krause, and co-authors have also investigated children's behavior with respect to the provision of public goods (Harbaugh and Krause, 2000), choices of lotteries (Harbaugh et al., 2002a) or of consumption goods (Harbaugh et al., 2001b), the endowment effect (Harbaugh et al., 2001a) as well as bargaining in ultimatum and dictator games (Harbaugh et al., 2003; see also Murnighan and Saxon, 1998). We discuss these papers in their relation to our findings in section 5.

${ }^{8}$ In the experiment of Harbaugh et al. (2002b), trustors had to make their decisions for five different trustees, each from a different age group (aged 8, 11, 14, 17 years or an adult). Trustees had to indicate their conditional return for each of five possible decisions of the trustor who could choose a transfer $x$ in integer amounts from zero to four tokens. 
based on two fully specified hypotheses from theoretical work in developmental psychology, which will be presented below.

The second strand of literature, addressing the influence of age on trust, has emerged only recently. Both Fehr et al. (2003) and Bellemare and Kröger (2003) have included an experimental trust game in a representative survey of German and Dutch households, respectively. Controlling for other socio-demographic factors like income and gender (which are both insignificant), both papers find that relatively older subjects (in particular those over 65) show less trust by choosing lower transfers $x$ than subjects in their thirties and forties. The degree of reciprocity (i.e., returns $y$ ) seems to increase with age. However, concerning the absolute quantities, the differences in trust and reciprocity between various adult age groups are rather small, even though statistically significant. ${ }^{9}$

Our study provides clear evidence that the most notable development of trust and development occurs from childhood to early adult age and that the influence of age is of rather minor importance across various adult age groups. Experiments based on representative surveys must necessarily miss the economically substantial changes in trust and reciprocity from childhood to student age because, generally, subjects aged below 18 are excluded from the samples. Furthermore, besides the problems associated with loosing control when running experiments in the framework of computerized representative surveys, we would like to mention that the existing studies with representative samples have failed to provide testable hypotheses with respect to the influence of age on trust and reciprocity. The lack of theoretical predictions is a consequence of the focus of standard economic theory, but one can resort to other disciplines in social science to derive testable predictions, as we will argue in the following subsection.

\footnotetext{
${ }^{9}$ In a mail-based semi-experimental trust game Holm and Nystedt (2002) find a similar effect of older adults showing less trust when comparing the behavior of 70 year olds with those of 20 year old students.
} 
Another, possibly confounding factor in the studies of Fehr et al. (2003) and Bellemare and Kröger (2003) is the fact that participants had no information on the age of their interaction partners. Consequently, the experimenters lost control, because subjects' behavior might actually depend on their (uncontrolled) expectation about the age of the interaction partner. This lack of control, which is especially important in cases where the difference in age is potentially large, might bias results if subjects actually behaved differently toward members of different age groups. In fact, there is some evidence by Holm and Nystedt (2002) that subjects have a strong preference to play a trust game with members of their own age cohort. This preference might actually be associated with, or even induce, different behavior toward members from different age groups. In order to avoid potentially confounding factors arising from not knowing the age of the interaction partner, subjects in our experiment are informed that they interact with members of their own age cohort.

\section{B. The limits of economic theory}

\section{and the relevance of developmental psychology}

Although the study of concepts like trust and reciprocity is perceived to be highly relevant for economics, economic theory reaches its limits where the evolution of trust and reciprocity with age is concerned. Obviously, traditional economic theory with its assumption of rational, money-maximizing agents is unable to explain trusting and reciprocal behavior in the trust game, because it predicts subjects to play the subgame-perfect Nash equilibrium of transferring nothing $(x=0)$. Consequently, several economic models have been developed lately (e.g., Bolton and Ockenfels, 2000; Charness and Rabin, 2002; Fehr and Schmidt, 1999) that take other-regarding preferences into account and are therefore much better able to account for the existence and stability of trust and reciprocity in human interactions. Yet none of these models on social preferences predicts an influence of age on trust and reciprocity, as they assume as given the extent of trust and reciprocity in economic interactions. 
Given the lack of guidance from economic theory, we have to resort to a field that deals primarily with the development of humans, although of course with an approach that has to be transformed into economic thinking and language. In developmental psychology, examining the development of trust and reciprocity has been part of a much broader research agenda on the development of 'prosocial' behavior. Basically, the latter term captures behavior which is not purely self-interested, but intends to benefit others as well (at varying costs to oneself). The study of prosocial behavior is an outgrowth of Piaget's (1932/1965) and Kohlberg's (1969) research on the development of moral judgment. Whereas Piaget and Kohlberg were mainly interested in the development of cognitive abilities and the stages of increasing sophistication of moral reasoning, the research on prosocial behavior links moral reasoning and cognitive or mental processes to actual behavior. Since behavior is strongly influenced by cognitive processes, it is no surprise that prosocial behavior and the development of moral reasoning are closely related. Consequently, as moral reasoning advances with age (Eisenberg et al., 1985; Boom et al., 2001), so the frequency of prosocial behavior generally also increases with age (Eisenberg and Mussen, 1989; Eisenberg and Fabes, 1998).

\section{Hypotheses}

Trust and reciprocity are two very important components or manifestations of prosocial behavior. The socialization of trust has been shown to start in the first few years of a person's life and works through parents instilling in their children trust in parents, relatives, and friends by letting children experience that they can rely on others (Rotenberg, 1995). Trust in strangers develops when children interact more frequently with strangers, which is typically the case when they enter kindergarten and school later on (Krebs and van Hesteren, 1994; Langford, 1997). Hence, trust is closely related to the number of contacts with others, which typically increases from childhood to the time of entering a working career, and stays more or 
less constant from that period on, with possibly a small decline in retirement (Kail and Cavanaugh, 2004). This leads us to our first hypothesis:

Hypothesis 1: Trust increases with age from childhood to (early) adult age. Hence, we expect the amount $x$, sent by the trustor to the trustee in the trust game, to increase with age.

Regarding the influence of age on reciprocity, most humans have been shown to rely on a material tit-for-tat strategy already at the age of 5 to 6 (Youniss, 1980, 1986), meaning that they return material rewards to interaction partners who provided them with material benefits in the first place. ${ }^{10}$ Hence, we would expect to observe the almost universal behavioral concept of reciprocity already at an early age, but the degree of reciprocity may be dependent on age, in particular when regarding the time span from childhood to early adulthood, since it has been shown that older subjects are better able to take into account the needs of other people and other relevant contextual information (Sigelman and Waitzman, 1991).

Hypothesis 2: Reciprocity is prevalent already at an early age. This means that we can expect a significantly positive relation between $y$ and $x$ in the trust game irrespective of age.

It is important to note here that, even though developmental psychology can provide useful insights into the development of trust and reciprocity with age, it has had only marginal influence on the economics literature so far. The reasons for this neglect are manifold. First,

\footnotetext{
${ }^{10}$ Note that the notion of 'a material tit-for-tat strategy' (even for young children) does not mean that subjects behave reciprocally only in repeated games. Reciprocity also applies in one-shot interactions (this is what Fehr et al., 2002, denote by 'strong reciprocity').
} 
developmental psychology does not provide rigorous (mathematical) theories or clear theoretical benchmarks - which are common in economics. Second, the experiments run in developmental psychology are, typically, not interactive and do not involve real money. Rather, participants are asked to hypothetically allocate a given amount of resources to themselves and other people or to resolve some social dilemma situations. However, economists believe in the value of material, mostly monetary, incentives for studying real behavior. Third, developmental psychology is by definition not primarily interested in the economic relevance of the development of human behavior in the course of a life cycle, but focuses on the psychological determinants of developments in behavior. Despite of these differences, we think that the insights of developmental psychology may be helpful to derive testable predictions for economic experiments in cases where the evolution of concepts affecting economic decision making is concerned.

\section{Experimental design}

\section{A. Parameters and protocol of decision making}

In our trust game, the trustor received 10 units of money $(X=10)$. The amount $x$, sent by the trustor to the trustee, was tripled. The trustee could then send back $y \leq 3 x$, yielding final payoffs of $10-x+y$ for the trustor, and $3 x-y$ for the trustee, respectively. ${ }^{11}$

The experiment was always run as a paper and pencil experiment where participants had to indicate their decision on a decision form. Trustors had to fill in the upper part of the decision form (given in Appendix B). Before transferring the decision form to a trustee, the

\footnotetext{
11 When we started the project with students, we allowed them to transfer and return also non-integer amounts. Since $86 \%$ of students, however, chose only integer amounts, we restricted the choice set to the integer numbers in all subsequent sessions with other age groups.
} 
experimenter entered the trustor's tripled transfer $(3 x)$ into the lower part of the decision form and canceled out those amounts (larger than $3 x$ ) which the trustee was unable to return. Then the trustee had to indicate the amount she wanted to return to the trustor.

In our experiment, the trustor was called "John/Joanna" and the trustee "Michelle/Michael."12 When running the experiment, we always started with one group (that is one class when running the experiments in schools) in which all subjects acted in the role of the trustor. They were given the instructions and told that they were to interact with some person of about the same age from another group, but that the identity of the other person would not be revealed. After having read the instructions aloud (a translated version of the German original is given in Appendix B), we answered all remaining questions in private. Then participants were asked to make their decision. They had to take their decision form out of an envelope, which also contained a paper slip with a code for later identification in order to be able to distribute profits. Trustors had to put back the decision form into the envelope after having marked their decision. In a second group, all participants acted in the role of trustees. They were also informed that the decision of the trustor had been made by a person of about the same age in another (unidentified) group or class. After going through the instructions and answering questions in private, they had to draw one of the envelopes, take out the paper slip with their identification code - which was put into the envelope after trustors had finished their part - and fill in their decision on the decision form.

\section{Table 1 about here}

\footnotetext{
12 We opted for these names (in the German instructions they were "Johann/Johanna" and "Michaela/Michael," respectively) and refrained from using the usually neutral labels 'person A' and 'person B' for the two roles (of trustor and trustee) in order to remain neutral with respect to gender and to stress (particularly in sessions with children) that the other party was also a real person.
} 
662 subjects from six different age groups participated in our trust game: (i) 8 year old second graders in primary school, (ii) 12 year old sixth graders, and (iii) 16 year old tenth graders in secondary school, (iv) students on average aged 22 years (standard deviation of 3.7), (v) working professionals on average aged 32 years (standard deviation of 11.5), and (vi) retired persons on average aged 68 years (standard deviation of 17.9). Table 1 reports the number of pairs (of one trustor and one trustee), the proportion of women, and the dates and places of the sessions in each age group. ${ }^{13}$

\section{B. Notes on our subject pool}

Since we informed subjects of all age groups that their interaction partner was from a different group or class, but of about the same age, we were careful to choose state schools with a large number of classes such that participants could not directly infer which other pupils served as participants in the other role. As regards the experiments in schools, a primary school in Salzburg (with about 300 pupils) and the secondary schools in Bregenz (1,000 pupils), Landeck (800 pupils), and Schwaz (400 pupils) were of a sufficient size for us. At the University of Innsbruck, which has about 25,000 students, we recruited participants from an email list that includes almost 2,000 students from all faculties who registered voluntarily for participation in experiments. Our working professionals were enrolled in a part-time (weekend) program for real estate and facility management either at the University of Applied Sciences in Innsbruck or in Kufstein (each of them with about 1,000 students in total). We chose participants from introductory economics classes and paired a class in Innsbruck with one in Kufstein. Regarding our pool of retired persons, we recruited the

\footnotetext{
${ }^{13}$ Due to different class sizes, it was not always possible to match exactly the number of trustors with the one of trustees. In this paper, we report only data for 'complete' pairs. All data points where either a trustor or a trustee was missing have been excluded.
} 
participants from athletic courses for retired persons at the Department of Sports of the University of Innsbruck and from the Tiroler Bildungsinstitut, an adult education institution which organizes seminars on various topics and for various age groups. We always paired a group from the Department of Sports with a group attending a course at the Tiroler Bildungsinstitut. Our post-experimental survey revealed that about $20 \%$ of the retired persons and about $12 \%$ of the working professionals held a university degree.

The schools we selected for experiments with 8 to 16 year old children have a long tradition and a high percentage (of about one half) of graduates that enroll at universities after their school-leaving exam. This ensures that participants from schools and our adult age groups have, on average, at least a similar socioeconomic background to our students, which was important for us in order to guarantee comparability.

\section{Specific features of running experiments with subjects from different age groups}

\section{C.1. Explaining the game (to children)}

Before running the experiments in primary school with our 8 year old children, we had to obtainconsent from the parents and the school board, the latter consisting of the school's director, teachers, and some parents. Since running experiments with young children involves the risk of difficulties in understanding, we were particularly careful to make sure there was full understanding of the experimental rules. For that purpose, we separately presented to each child in the role of trustor a table which indicated the amount of disposable money for the trustor and the trustee for each possible transfer $x$. Children in the role of trustee were told how much money (out of the ten units of money) the trustor had sent them and how much the trustor and the trustee would earn for each possible return $y$. We opted for this procedure after 
having sought advice from class teachers on how to present the possible states of the game. The teachers suggested to present all possible distributions and not only two or three examples, because in the latter case decisions might be focused on the examples. Sessions lasted about 50 minutes, and we felt certain that the 8 year old children understood the nature of the game and their strategic options.

In the secondary school, we only needed the consent of the school's director and the respective class teachers to run the experiments. We read the instructions aloud and gave subjects plenty of time to ask questions. Before distributing the decision forms, we asked each participant individually whether she had understood the rules of the game perfectly or whether she had any further questions. Sessions with secondary school children lasted about 45 minutes. Sessions with students, professionals, and retired persons lasted only 30 minutes, although the procedure was identical. But we did not ask individually whether there were any open questions, but gave participants enough time to raise their hand and ask questions privately if necessary. ${ }^{14}$

\footnotetext{
${ }^{14}$ When we started the project with student sessions (which are partly used in a paper on gender differences of student participants in experimental trust games, see Schwieren and Sutter, 2003), we used a postexperimental trust questionnaire (Yamagishi, 1988). However, none of the questions concerning trust or trustworthiness separately nor the trust scale to be computed as a sum of the answers turned out to have any explanatory power for behavior in the experiment. Glaeser et al. (2000) also found that in experiments only trustworthiness (the behavior of the trustee), but not the willingness to trust (the behavior of the trustor), corresponds to participants' responses to survey measures of trust (see also the discussion in Fehr et al., 2003). Since Harbaugh et al. (2002b) even found a negative correlation between the amount sent by the trustor and her response to the question “Overall, can you trust most people?", we abstained from using any postexperimental questionnaire on trust for our other age groups. There seems to be evidence, however, that trust scales from questionnaires are correlated with behavior in other experimental games, as Gächter et al. (2004) have shown recently for experimental public good games.
} 


\section{C.2. Possible endowment effects}

In each experimental session, the trustor received an endowment of 10 units of money. Since we wanted to be able to compare directly treatments with participants of different age, we kept the money value of the endowment initially constant across age groups. To be precise, we set an exchange rate of 50 euro cent per unit of money, yielding a total endowment of $5 €$ for the trustor. ${ }^{15}$

An obvious argument against our constant stakes would be that they imply different relative stakes for different age groups. What is a considerable amount of money for young children, is a small amount for working professionals. Although experimental economics has gathered ample evidence which does not support the conjecture that higher stakes change behavior very much, ${ }^{16}$ we wanted to be on the safe side here and tested for stake effects by conducting several additional experimental sessions in which participants' endowment was worth either $2 €$ or $8 €$. It turned out that - within a given age group - the degree of trust and reciprocity does not depend on the monetary value of the endowment. Therefore we decided to pool the data within a given age group and present our results on an aggregate level. Disaggregated results with regard to different endowment levels can be found in Table A.1 in the Appendix, where we also present statistical evidence for our claim that relative stakes do not play a role here.

\footnotetext{
${ }^{15}$ There is one notable exception: The school board of the primary school determined that we should use only $2 €$ as endowment (but not $5 €$ or other rewards such as candies, as is often done). $2 €$ is equivalent to the average weekly allowance of 8 year old children and therefore still a reasonable monetary incentive for them.

${ }^{16}$ See Camerer (2003) or Camerer and Hogarth (1999) for an overview of the influence of stake sizes on behavior in experiments.
} 


\section{Experimental results}

In Table 2, we present an overview of our results. Aggregating over all age groups and endowments, trustors send on average 5.11 out of 10 units of money to trustees. Trustees return on average only slightly more (5.37) than they have received, implying that trust does not increase a trustor's payoff by much, on average, compared to a situation where the trustor keeps the whole endowment for him-/herself. Overall, average earnings of trustors and trustees are remarkably close to each other (10.14 vs. 10.08). Average total payoffs for a pair amount therefore to about two thirds of the maximally achievable level (of 30 units of money for trustor and trustee together).

\section{Table 2 about here}

\section{A. Trust and age: Trustor behavior}

Figure 1 shows that age has a strong effect on trustor behavior. In particular, we find that transfers $x$ monotonically increase from 8 year old children to students, ranging from 2.0 for primary school children to about 6.6 out of 10 units of money for students. ${ }^{17}$ Within our adult groups of students, professionals, and retired persons, we find that average transfers are almost identical for students and professionals, and (insignificantly) lower in our group of retired persons. The latter group constitutes the only case where transfers decrease with

\footnotetext{
${ }^{17}$ Looking at individual data (see the raw data in the Appendix) we find that 8 year olds and 12 year olds show the highest frequencies of sending nothing $(x=0 ; N=5$ or $11 \%$ for 8 year olds; $N=6$ or $10 \%$ for 12 year olds), whereas students have the highest tendency of sending their full endowment to the trustee $(x=10 ; N=44$ or $40 \%)$.
} 
increasing age. ${ }^{18}$ In all other cases, transfers increase monotonically - and significantly - with increasing age, which is overwhelmingly supported by a non-parametric Jonckheere-test $(\mathrm{p}<$ 0.001). We therefore find firm support for Hypothesis 1, which stated that trust, that is the transfer $x$, is expected to increase with age, at least until early adulthood. ${ }^{19}$ Among our adult participants, average transfers are not significantly different between students, professionals, or retired persons, implying that the development of trust reaches a rather stable level already during the time of early adulthood.

Figure 1 about here

\section{B. Reciprocity and age: Trustee behavior}

Before examining in greater detail the influence of age on reciprocity, that is the relation between the return $y$ and the transfer $x$, we start by looking at returns. Absolute returns $y$, in general, increase with age (see Figure 2). Since we have no directional hypothesis concerning the development of returns with age, we apply a non-parametric Kruskal-Wallis test to examine differences in returns across age groups, which yields highly significant results $(p<$ $0.001)$

\section{Figure 2 about here}

\footnotetext{
${ }^{18}$ Within a given age group, there are no significant differences between transfers or returns of men and women. A table of average transfers and returns of men and women in the different age groups is available from the authors on request.

${ }^{19}$ Note that there is a perfect correlation of transfer levels and relative efficiency in the trust game. Thus, we can conclude that relative efficiency, defined as the ratio of a pair's actual payoffs and its maximum payoff (of 30 units) increases with age.
} 
Given that transfer rates differ across age groups, the latter finding is, of course, no surprise. Therefore a straightforward next step is to look at relative returns $y / 3 x$, where we also find significant differences across age groups according to a Kruskal-Wallis test $(p<$ 0.001). Yet we can distinguish three sets of age groups with respect to relative returns, as can also be discerned from Figure 3. The first set is the group of 8 and 12 year old children with the comparatively lowest relative returns (ranging from $10 \%$ to $15 \%$ ). The second set comprises 16 year old children, students, and professionals, who return between $31 \%$ and $39 \%$ of the received money. ${ }^{20}$ The third set comprises retired persons, who return on average more than half of the received amount (57\%), which is significantly higher than the relative return of any other age group ( $p<0.05$ in any pairwise comparison; two-sided U-test).

\section{Figure 3 about here}

As claimed by Hypothesis 2, we expect a significantly positive dependence of the return $y$ on the transfer $x$, irrespective of age. In order to test this hypothesis rigorously, we use a twosided, flexibly censored tobit-mode ${ }^{21}$ to regress returns $y$ on transfers $x$. The left-hand side censoring is zero, and the right-hand side censoring has been set at $3 x$, which allows for a flexible right-hand side upper level of returns, depending on the specific transfer $x$. All observations with transfers of $x=0(N=18$ in total $)$ are discarded from the tobit regression since the trustee had no choice but to return $y=0$ in these cases.

Table 3 shows the regression results, separately for our six different age groups as well as overall. In each single age group, the slope of the censored regression, and thus the marginal

\footnotetext{
${ }^{20}$ There is no statistically significant difference between relative returns within the second set, but any age group of the second set returns significantly higher relative amounts $(y / 3 x)$ than 8 and 12 year old children $(p<$ 0.05 in any pairwise comparison; two-sided U-test).

${ }^{21}$ Our basic results do not change when we use ordered probit estimations instead of censored tobit.
} 
effect of the transfer $x$ on the return $y$ (given that $y$ is not censored), is significantly positive. This result supports Hypothesis 2. As regards the marginal effects of transfers on returns, professionals react strongest to an increase in transfers by returning an estimated 1.7 units of money for one additional unit of transfers (which, of course, is tripled for the trustee). The marginal effect for professionals is (for some comparisons, weakly) significantly larger than for any other age group, except for students.

\section{Tables 3 and 4 about here}

Table 4 reports an encompassing, two-sided, flexibly censored tobit regression with professionals as reference group and dummies for all other age groups (to test for differences in intercepts) and interaction terms of dummies with the transfer $x$ (to test for differences in the slopes). Intercepts, that is the amounts returned independent of the size of transfers, are significantly smaller in our group of professionals than with 16 year old children or retired persons. The latter two age groups have significantly higher intercepts than any other age group, whereas the remaining four age groups do not differ from each other with regard to intercepts. Our reference group of professionals showsa significantly steeper slope, that means a higher responsiveness to transfer levels, than all other age groups, with the exception of students.

In sum, our results provide clear support for Hypothesis 2, confirming that reciprocity exists already at an early age and prevails also in later stages of human life. However, judging from Tables 3 and 4, there also seems to be a development of reciprocity with age such that marginal effects are increasing from young children to working professionals. Younger children show less pronounced reciprocal behavior than older children or adults. Our group of professionals is really outstanding in this respect because they react very strongly to an increase in the transfer $x$. 


\section{Transfers, returns, and profits - A final assessment}

At the end of this section, we would like to address briefly the implications of trusting behavior for the first moving player, the trustor, in terms of payoffs. For that purpose, we calculate the ex-post expected profits of trustors, given the actual average returns for each possible transfer.

\section{Figure 4 about here}

As can be discerned from Figure 4 with our three youngest age groups, the ex-post payoff-maximizing strategy for the group of 8 and 12 year old children is to transfer nothing $(x=0)$. For 8 year old children, the ex-post expected profit is even monotonically decreasing with transfers from $x=0$ to $x=5 .{ }^{22}$ From this perspective, the very low transfers of 8 year olds and 12 year olds can be rationalized ex post, in the sense that they were payoffmaximizing. Only for 16 year old trustors, there are - ex post - more profitable alternatives than choosing $x=0$. However, the series of ex-post expected profits is rather unsteady and shows no clear pattern.

Figure 5, presenting the ex-post expected profits for our adult age groups, shows that high transfers (with $x \geq 8$ ) raise trustors' ex-post expected profits in any age group, compared with the benchmark solution of $x=0$. Actually, for retired trustors any positive transfer raises expost expected payoffs as compared to sending nothing. In our groups of students and

\footnotetext{
${ }^{22}$ There is just a single observation for $x=10$, however, which yielded a return of only 8 units of money. From $x=6$ to $x=9$, the series for 8 year old children is broken because there were no such transfers. Similarly, there are missing points in other age groups where we had no observations of the respective transfer. Furthermore, the number of observations for each possible transfer varies considerably since we deliberately have chosen not to apply the strategy vector method. The peak in our group of retired persons for $x=7$ (see Figure 5), e.g., is a single observation.
} 
professionals, one can see that showing 'a little bit of trust' (choosing low to intermediate transfers) seems to be perceived as a signal of 'mistrust' rather than of trust and is therefore not fully rewarded by the trustee. Very high levels of trust $(x \geq 9)$, however, raise final ex-post expected payoffs for the trustor on average about $30 \%$ to $50 \%$ above his initial endowment. ${ }^{23}$

\section{Figure 5 about here}

\section{Discussion and conclusion}

Trust in strangers increases significantly with age, and reciprocity is a prevailing pattern of behavior already at the age of 8 , although its degree increases with age, making trust more profitable and economic exchanges more efficient when interaction takes place among adults rather than among children. These are the key results of our experimental study on the development of trust and reciprocity with age.

Our findings are completely in line with predictions derived from theory and existing evidence in developmental psychology. The novel feature here - compared to developmental psychology - is the fact, however, that we have studied an interactive decision-making task with real, monetary incentives instead of asking children or adults hypothetical questions on their preferred allocation of money in relevant dilemma situations. A further unique characteristic of our study - compared to existing economic contributions - is that we ran identical experimental sessions with participants ranging in age from childhood to retirement.

Some aspects of our results require a more thorough discussion. As mentioned above, in our version of the trust game, inequity aversion or other forms of social preferences might, of

\footnotetext{
23 The finding that 'partial' trust usually does not pay off, whereas (almost) full trust raises the trustor's payoff above his initial endowment, seems to be typical for student subject pools (see Bolle, 1998, Pillutla et al., 2003).
} 
course, also account for parts of the transfer $x$ chosen by the trustor. Regardless whether only the trustor receives an initial endowment (our design) or both the trustor and the trustee (the design of Berg et al., 1995), ${ }^{24}$ it is always difficult to disentangle the influence of various factors, like trust, trustworthiness, efficiency preferences, inequity aversion, altruism, or reciprocity, on behavior in trust games. We know from the triadic game design developed by Cox (2004) that a considerable part of the transfer $x$ can be regarded as trust. For the sake of succinctness of language, we interpret $x$ as a measure of trust throughout this study, bearing in mind that other factors may have an influence as well. In the following, we would like to argue, however, that two other possible determinants of behavior of trustors, altruism and risk aversion, cannot account for the different behavior of different age groups in our trust game.

Harbaugh and Krause (2000) find no differences in altruistic preferences between 6 to12 year old children and adults in the first round of a public good game or in a dictator game. ${ }^{25}$ Hence, we can conclude that there does not seem to be an increase in unconditional altruistic preferences with age, which could have provided an alternative explanation for our finding of an increase in transfers $x$. Consequently, the higher transfers with age can only be explained by an increase in trust, which is also what developmental psychology would predict.

Harbaugh et al. (2002a) have studied children's choices in risky lotteries, showing that children are more likely to choose the same set of risky lotteries than adults. The trustor's decision on the transfer $x$ in a trust game is obviously risky since the former cannot know the return $y$ from 'investing' $x$ in advance. The difference between lotteries and the trust game is, of course, that lotteries are noninteractive and have a fixed probability of winning, whereas in the trust game the trustor's payoff depends on another subject's decision. Whereas children

\footnotetext{
${ }^{24}$ Note that our results for adult participants are quantitatively in line with the results of adult participants in trust games under the Berg et al. design (see Camerer, 2003), showing that the difference in the designs does not seem to lead to systematic behavioral differences.

${ }^{25}$ Repetition, however, seems to affect children and adults differently.
} 
choose the same risky lotteries more often than adults, children choose higher risks (that is a higher $x$ ) less often than adults in our trust game. This indicates that our results are not driven by differences in risk attitudes between subjects of different age, but rather by differences in trust.

In summary, we regard our results as important for a better understanding of the origins of other-regarding behavior and the development of homo oeconomicus into homo reciprocans (Fehr and Gächter, 2000), the latter being characterized by showing trust and reciprocity in the presence of incomplete contracts, thereby providing a firm basis for the smooth and efficient functioning of society in general and of market economies in particular. The reason for the correlation of trusting behavior and age until early adulthood is supposed to lie in the gradual integration of young people into society that inevitably includes a rising number of encounters with strangers or even widely anonymous people (via the Internet or the phone, for instance).

Though our study is able to provide a comprehensive empirical assessment on the level of trust and reciprocity across different age groups, it must leave some questions open for future research and poses a few further questions itself. One natural extension of our experimental design would be a treatment in which two subjects from different age groups interact with each other directly, where both know the age group of the interaction partner. Holm and Nystedt (2002) have found a strong preference of subjects to play the trust game with members of their own age cohort. Even though this endogenous selection does not immediately imply that subjects trust members of other age cohorts less, it is an indication that social capital could be larger within a given age group than between different age groups.

The slight decrease of trust from working professionals to retired persons is an interesting phenomenon in itself and deserves deeper analysis. It seems to be the case that the level of trust is not monotonically increasing across the full age spectrum, but reaches a peak somewhere around the age of 30 or 40. The findings of Fehr et al. (2003) or Fehr and List 
(2002) provide further evidence for this observation. But it remains an open question why the level of trust seems to decrease beyond the age of 40 , in particular in retirement, and whether this can be explained by the decrease in personal contacts and encounters, which typically accompanies retirement (compared to working life).

Finally, a long-term research project, which seems promising in the light of our results, would be to examine the development of trust and reciprocity in economic relationships in a longitudinal study by observing subjects for several years, thereby taking them as their own control. It seems reasonable to assume that the level of trust and reciprocity does not only differ across different age groups at the same time, but also develops across time within a given age group. We leave it for further research to investigate this assumption. 


\section{Literature}

Alesina, A., La Ferrara, E. (2002), Who trusts others? Journal of Public Economics 85: 207-34.

Bellemare, C., Kröger, S. (2003), On representative trust. University of Tilburg. Working Paper.

Berg, J., Dickhaut, J., McCabe, K. (1995), Trust, reciprocity, and social history. Games and Economic Behavior 10: 121-42.

Bewley, Truman F. (1999), Why Wages Don't Fall During a Recession. Harvard University Press.

Bolle, F. (1998), Does trust pay? Europa-Universität Viadrina Frankfurt/Oder. Working Paper.

Bolton, G. E., Ockenfels, A. (2000), ERC - A theory of equity, reciprocity and competition. American Economic Review 90: 166-93.

Boom, J., Brugman, D., van der Heijden, P. G. M. (2001), Hierarchical structure of moral stages assessed by a sorting task. Child Development 72: 535-48.

Bornstein, G., Kocher, M. G., Kugler, T., Sutter, M. (2003), Whom should you trust more in bargaining? Groups or individuals? Mimeo. Hebrew University of Jerusalem.

Camerer, C. F. (2003), Behavioral Game Theory. Experiments in Strategic Interaction. Princeton University Press.

Camerer, C. F., Hogarth, R. M. (1999), The effects of financial incentives in experiments: A review and capital-labor-production framework. Journal of Risk and Uncertainty 19: 7-42.

Charness, G., Rabin, M. (2002), Understanding social preferences with simple tests. Quarterly Journal of Economics 117: 817-69.

Cox, J. C. (2002), Trust, reciprocity, and other-regarding preferences: Groups vs. individuals and males vs. females. in: Rami Zwick and Amnon Rapoport, (eds.), Advances in experimental business research. Kluwer Academic Publishers.

Cox, J. C. (2004), How to identify trust and reciprocity. Games and Economic Behavior, forthcoming.

Cox, J. C., Deck, C. A. (2002), When are women more generous than men? Mimeo, University of Arizona.

Croson, R., Buchan, N. (1999), Gender and culture: International experimental evidence from trust games. American Economic Review, Papers and Proceedings 89: 386-91.

Durlauf, S. N. (2002), On the empirics of social capital. Economic Journal 112: F459-79. 
Eisenberg, N. Boehnke, K., Schuhler, P., Silbereisen, R. K. (1985), The development of prosocial behavior and cognitions in German children. Journal of Cross-Cultural Psychology 16: 69-82.

Eisenberg, N., Fabes, R. A. (1998), Prosocial development. in: Damon, W. (ed.), Handbook of Child Psychology. J. Wiley.

Eisenberg, N., Mussen, P. (1989), The Roots of Prosocial Behavior in Children. Cambridge University Press.

Fehr, E., Falk, A. (1999), Wage rigidity in a competitive incomplete contract market. Journal of Political Economy 107: 106-34.

Fehr, E., Fischbacher, U., Gächter, S. (2002), Strong reciprocity, human cooperation and the enforcement of social norms. Human Nature 13: 1-25.

Fehr, E., Fischbacher, U., von Rosenbladt, B., Schupp, J., Wagner, G. G. (2003), A nationwide laboratory. Examining trust and trustworthiness by integrating behavioral experiments into representative surveys. Institute for Empirical Research in Economics. Working Paper 141. University of Zurich.

Fehr, E., Gächter, S. (2000), Fairness and retaliation - The economics of reciprocity. Journal of Economic Perspectives 14: 159-84.

Fehr, E., Gächter, S., Kirchsteiger, G. (1997), Reciprocity as a contract enforcement device. Econometrica 65: 833-60.

Fehr, E., Kirchsteiger, G., Riedl, A. (1993), Does fairness prevent market clearing? An experimental investigation. Quarterly Journal of Economics 108: 437-60.

Fehr, E., List, J. A (2002), The hidden costs and returns of incentives - Trust and trustworthiness among CEOs. Working Paper 134. University of Zurich, Institute for Empirical Research in Economics.

Fehr, E., Schmidt, K. (1999), A Theory of fairness, competition, and cooperation. Quarterly Journal of Economics 114: 817-68.

Gächter, S., Herrmann, B., Thöni, C. (2004), Trust, voluntary cooperation, and socio-economic background: Survey and experimental evidence. Journal of Economic Behavior and Organization, forthcoming. 
Glaeser, E. L., Laibson, D., Sacerdote, B. (2002), An economic approach to social capital. Economic Journal 112: F437-58.

Glaeser, E., Laibson, D. I., Scheinkman, J. A., Soutter, C. L. (2000). Measuring trust. Quarterly Journal of Economics 115: 811-46.

Harbaugh, W. T., Krause, K. (2000), Children's altruism in public good and dictator experiments. Economic Inquiry 38: 95-109.

Harbaugh, W. T., Krause, K., Vesterlund, L. (2001a), Are adults better behaved than children? Age, experience, and the endowment effect. Economics Letters 70: 175-81.

Harbaugh, W. T., Krause, K., Berry, T. R. (2001b), GARP for kids: On the development of rational choice behavior. American Economic Review 91: 1539-45.

Harbaugh, W. T., Krause, K., Vesterlund, L. (2002a), Risk attitudes of children and adults: Choices over small and large probability gains and losses. Experimental Economics 5: 53-84.

Harbaugh, W. T., Krause, K., Liday, S. G. Jr., Vesterlund, L. (2002b), Trust in children. in: Ostrom, E., Walker, J. (eds.), Trust, Reciprocity and Gains from Association: Interdisciplinary Lessons from Experimental Research. New York City. Russell Sage Foundation, forthcoming.

Harbaugh, W. T., Krause, K., Liday, S. G. Jr. (2003), Children's bargaining behavior. Working Paper, University of Oregon.

Holm, H., Nystedt, P. (2002), Intra-generational trust - a semi-experimental study of trust among different generations. University of Lund. Working Paper, May 2002.

Kail, R. V., Cavanaugh, J. C. (2004), Human Development: A Life-Span View. Wadsworth Publishing.

Knack, S., Keefer, P. (1997), Does social capital have an economic payoff? Quarterly Journal of Economics 112: 1251-73.

Kohlberg, L. (1969), Stage and sequence: The cognitive-developmental approach to socialization. in: Goslin, D. A. (ed.), Handbook of Socialization Theory and Research. Rand McNally.

Kovalchik, S., Camerer, C. F., Grether, D. M., Plott, C. R., Allman, J. M. (2004), Aging and decision making: A broad comparative study of decision behavior in neurologically healthy elderly and young individuals. Journal of Economic Behavior and Organization, forthcoming. 
Krebs, D. L., van Hesteren, F. (1994), The development of altruism: Toward an integrative model. Developmental Review 14: 103-58.

Langford, P. E. (1997), Separating judicial from legislative reasoning. Child Development 68:1105-16.

Mayer, R. C., Davis, J. H., Schoorman, F. D. (1995), An integrative model of organizational trust. Academy of Management Review 20: 709-34.

McNeal, J. U. (1992), The littlest shoppers. American Demographics 14 (2): 48-53.

Murnighan, J. K. Saxon, M. S. (1998), Ultimatum bargaining by children and adults. Journal of Economic Psychology 19: 415-45.

Piaget, J. (1932/1965), The Moral Judgment of the Child. Free Press.

Pillutla, M. M., Malhotra, D., Murnighan, J. K. (2003), Attributions of trust and the calculus of reciprocity. Journal of Experimental Social Psychology 39: 448-55.

Rotenberg, K. J. (1995), The socialisation of trust: Parents' and children's interpersonal trust. International Journal of Behavioral Development 18: 713-26.

Rousseau, D. M., Sitkin, S. B., Burt, R. S., Camerer, C. F. (1998), Not so different after all: A crossdiscipline view of trust. Academy of Management Review 23: 393-404.

Schwieren, C., Sutter, M. (2003), Trust in cooperation or ability? An experimental study on gender differences. University of Innsbruck. Working Paper, July 2003.

Sigelman, C. K., Waitzman, K. A. (1991), The development of distributive justice orientations: Contextual influences on children's resource allocations. Child Development 62: 1367-78.

Yamagishi, T. (1988), The provision of a sanctioning system in the United States and Japan. Social Psychology Quarterly 51: 265-71.

Youniss, J. (1980), Parents and Peers in Social Development. University of Chicago Press.

Youniss, J. (1986), Development in reciprocity through friendship. in: Zahn-Waxler et al. (eds.), Altruism and Aggression: Biological and Social Origins. Cambridge University Press.

Zak, P. J., Knack, S. (2001), Trust and growth. Economic Journal 111: 295-321. 


\section{Tables and Figures}

Table 1. Number of pairs per age group

\begin{tabular}{lccccc}
\hline \hline Age group & $\begin{array}{c}\text { Number of } \\
\text { pairs }\end{array}$ & $\begin{array}{c}\text { Women } \\
\text { (in \%) }\end{array}$ & Date of & Institution & Place \\
& 45 & 51 & $11 / 02$ & primary school & Salzburg \\
\hline 8 years ( ${ }^{\text {nd }}$ graders) & 61 & 50 & $06+10 / 02+09 / 03$ & secondary school & Bregenz/Landeck/Schwaz \\
12 years ( $6^{\text {th }}$ graders) & 50 & 55 & $06+10 / 02+09 / 03$ & secondary school & Bregenz/Landeck/Schwaz \\
16 years (10 ${ }^{\text {th }}$ graders) & 110 & 48 & $01 / 02+10 / 03$ & university & Innsbruck \\
Students (avg. age 22 ) & 31 & 33 & $03+04 / 03$ & university of & Innsbruck/Kufstein \\
Professionals (avg. age 32) & & & & applied sciences & Innsbruck \\
Retired persons (avg. age 68) & 34 & 78 & $03+07 / 03$ & adult education & \\
\hline Total & 331 & 51 & & & \\
\hline \hline
\end{tabular}

Table 2. Average transfers, returns and profits

\begin{tabular}{|c|c|c|c|c|c|c|}
\hline Age group & $\begin{array}{l}\text { Trustor's } \\
\text { transfer } x\end{array}$ & $\begin{array}{l}\text { Trustee's } \\
\text { return } y\end{array}$ & $\begin{array}{c}\text { Relative } \\
\text { return } y / 3 x\end{array}$ & $\begin{array}{c}\text { Trustor's } \\
\text { profit }\end{array}$ & $\begin{array}{c}\text { Trustee's } \\
\text { profit }\end{array}$ & $\begin{array}{l}\text { Pairs } \\
\text { (N) }\end{array}$ \\
\hline 8 years $\left(2^{\text {nd }}\right.$ graders $)$ & 2.00 & 0.66 & 0.10 & 8.64 & 5.36 & 45 \\
\hline 12 years $\left(6^{\text {th }}\right.$ graders $)$ & 3.61 & 2.04 & 0.15 & 8.22 & 9.00 & 61 \\
\hline 16 years $\left(10^{\text {th }}\right.$ graders $)$ & 5.46 & 5.16 & 0.32 & 9.70 & 11.22 & 50 \\
\hline Students (avg. age 22) & 6.56 & 7.06 & 0.31 & 10.49 & 12.63 & 110 \\
\hline Professionals (avg. age 32) & 6.58 & 9.03 & 0.39 & 12.16 & 11.00 & 31 \\
\hline Retired persons (avg. age 68) & 5.38 & 8.65 & 0.57 & 13.26 & 7.50 & 34 \\
\hline All observations & 5.11 & 5.37 & 0.29 & 10.14 & 10.08 & 331 \\
\hline
\end{tabular}


Table 3. Tobit regression of return y on transfer $x$

\begin{tabular}{|c|c|c|c|c|c|c|c|}
\hline & & & Maginal & & & & \\
\hline Age group & Intercept & Slope & effect $t^{\mathrm{a}}$ & Adjusted $R^{2}$ & $N(x>0)$ & censored & censored \\
\hline 8 years $\left(2^{\text {nd }}\right.$ graders $)$ & $-1.92 * *$ & $0.74^{* *}$ & $0.31 * *$ & 0.56 & 40 & 23 & 0 \\
\hline 12 years $\left(6^{\text {th }}\right.$ graders $)$ & $-2.44 * *$ & $1.00^{* *}$ & $0.69 * *$ & 0.54 & 55 & 17 & 0 \\
\hline 16 years $\left(10^{\text {th }}\right.$ graders $)$ & -0.18 & $0.97 * *$ & $0.81^{* *}$ & 0.33 & 49 & 5 & 3 \\
\hline Students (avg. age 22) & $-4.26^{* *}$ & $1.61 * *$ & $1.25^{* *}$ & 0.48 & 106 & 20 & 4 \\
\hline Professionals (avg. age 32) & -6.43 & $2.26^{* *}$ & $1.73^{* *}$ & 0.35 & 30 & 3 & 4 \\
\hline Retired persons (avg. age 68) & 4.12 & $0.94 *$ & $0.79 *$ & 0.20 & 33 & 0 & 5 \\
\hline Overall & $-3.96^{* *}$ & $1.62 * *$ & $1.19 * *$ & 0.49 & 313 & 67 & 16 \\
\hline
\end{tabular}

* (**) significantly different from zero at the 5\%- (1\%-) level

${ }^{a}$ Marginal effects of $x$ on $y$ (for cases where $y$ is uncensored, i.e., $y>0$ and $y<3 x$ ) are computed by multiplying the slope with the ratio of the number of uncensored observations to the number of total observations.

Table 4. Tobit regression with age group dummies

\begin{tabular}{|c|c|}
\hline Dependent variable: return y & coefficient \\
\hline Constant & $-5.56 * *$ \\
\hline $\operatorname{transfer} x$ & $2.13^{* * *}$ \\
\hline dummy 8 year olds & 1.13 \\
\hline dummy 12 year olds & 1.11 \\
\hline dummy 16 year olds & $5.48^{*}$ \\
\hline dummy students & 1.53 \\
\hline dummy retired persons & $9.78 * * *$ \\
\hline dummy 8 year olds $*$ transfer $x$ & $-1.14^{*}$ \\
\hline dummy 12 year olds $*$ transfer $x$ & $-0.85 *$ \\
\hline dummy 16 year olds $*$ transfer $x$ & $-1.19 * * *$ \\
\hline dummy students $*$ transfer $x$ & -0.54 \\
\hline dummy retired persons $*$ transfer $x$ & $-1.21 * *$ \\
\hline adjusted $R^{2}$ & 0.55 \\
\hline log likelihood & -759.1 \\
\hline$N(x>0)$ & 313 \\
\hline left-censored observations $(y=0)$ & 68 \\
\hline right-censored observations $(y=3 x)$ & 16 \\
\hline
\end{tabular}


Figure 1. Average transfers $x$

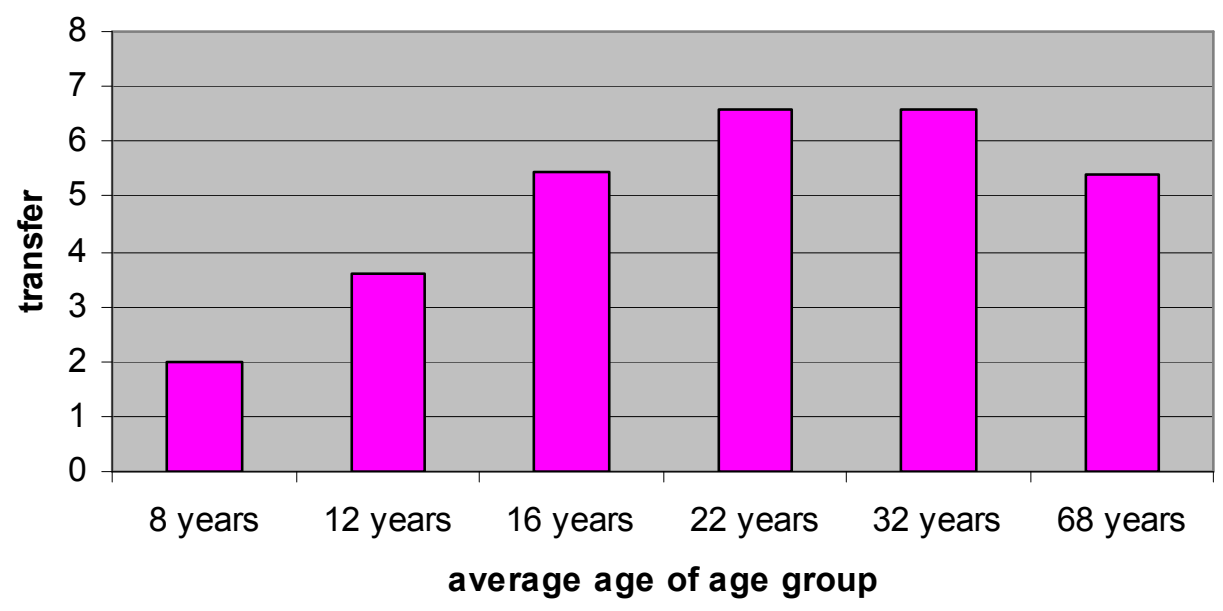

Figure 2. Average returns y

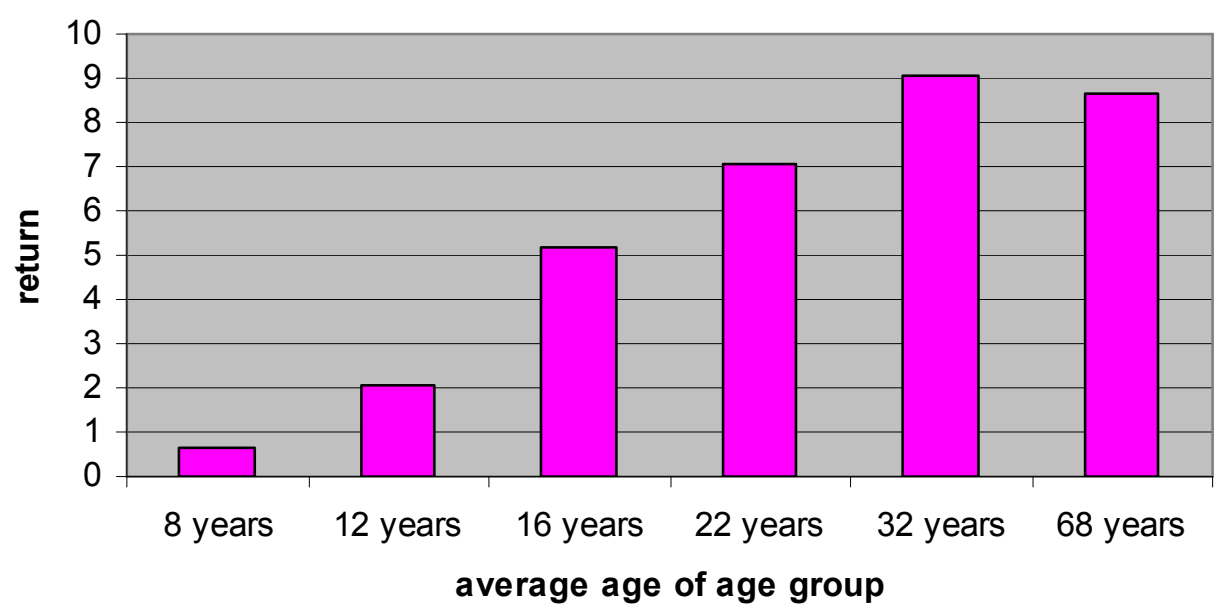

Figure 3. Average relative returns $y / 3 x$

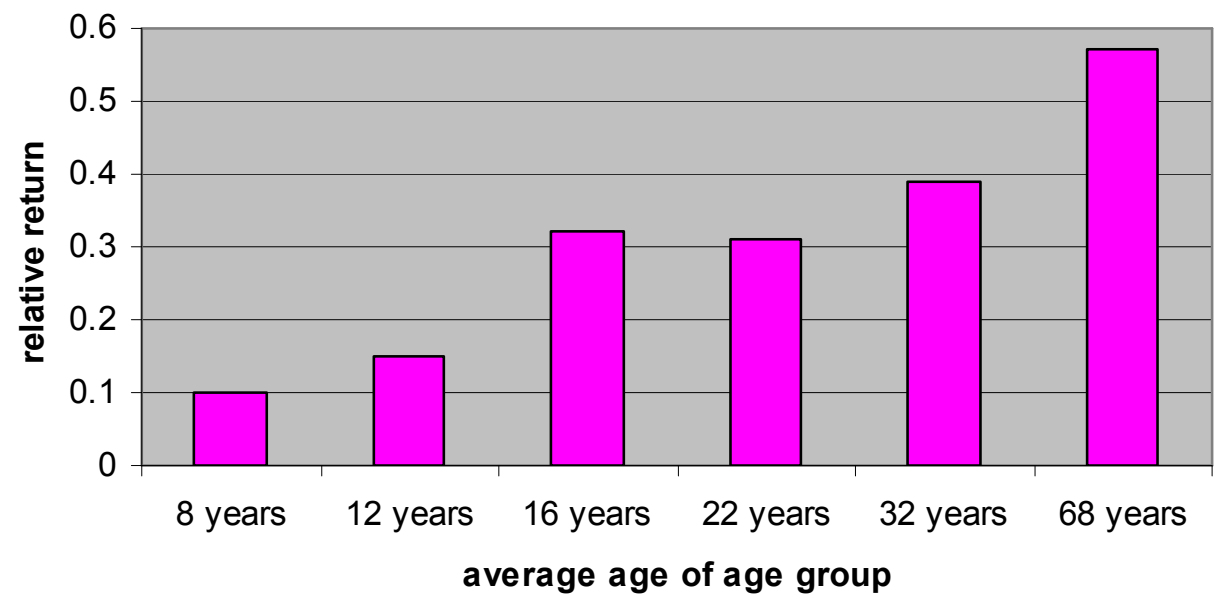


Figure 4. Expected profit of trustor - Children

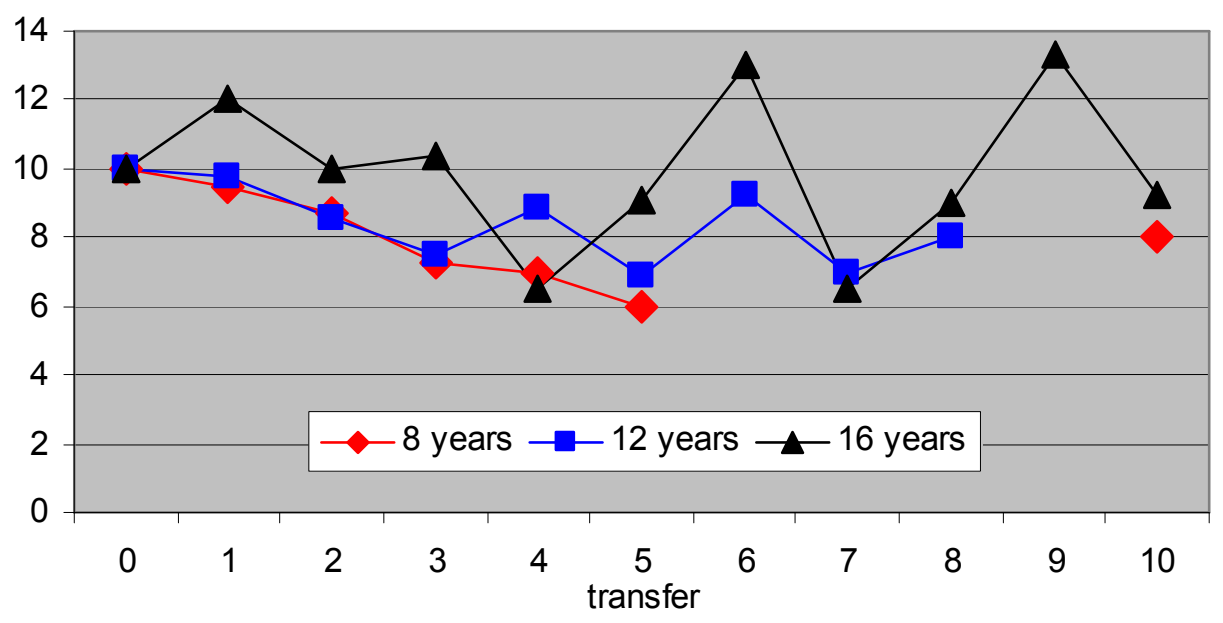

Figure 5. Expected profit of trustor - Adults

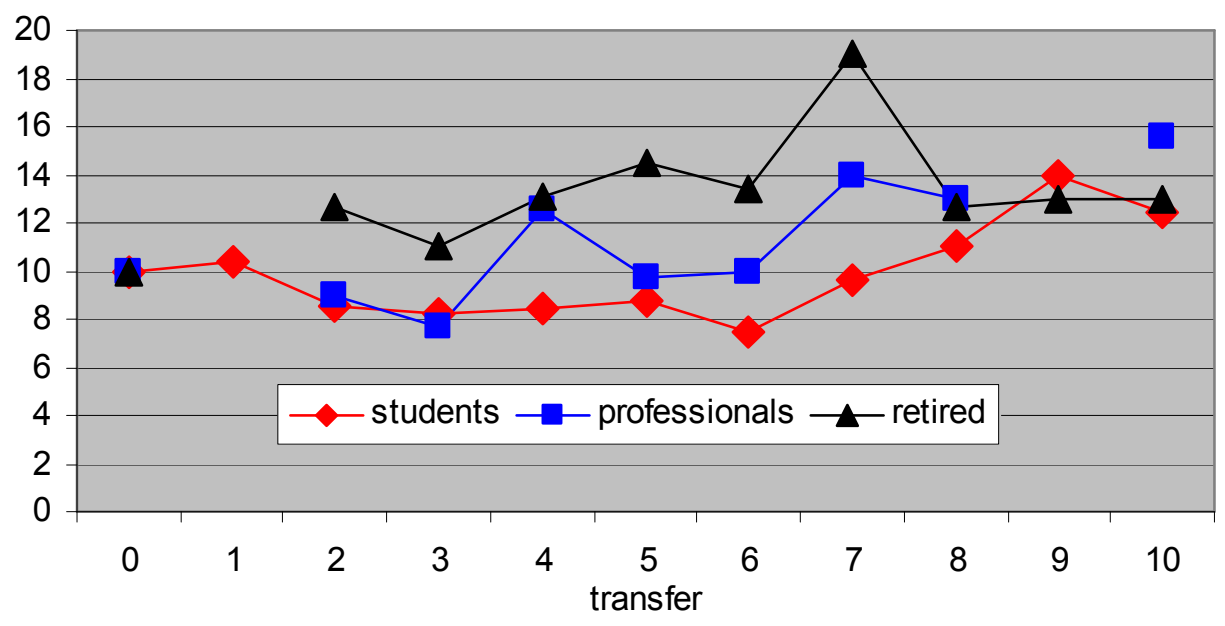




\section{Appendix A - Endowment effects}

In Table A.1, we present an overview of our results with different endowments. In particular, we display for each age group and value of the trustor's endowment $(2 € / 5 € / 8 €)$ [a] the trustors' average transfers $x$ in units of money (with the number of observations, i.e., pairs, in brackets), [b] trustees' average absolute $(y)$ and [c] relative $(y / 3 x)$ returns, and [d] the respective profits. A variation in endowments allows us to compare the behavior under different endowments within a given age group and to keep the relative stakes sufficiently constant across different age groups, for instance by comparing 12 year olds with $2 €$ endowment to 16 year olds with $5 €$ endowment and to 22 year old students with $8 €$ endowment.

Table A.1. Average transfers, returns, and profits for different endowments and age groups

\begin{tabular}{|c|c|c|c|c|c|c|}
\hline Age group & 8 years & 12 years & 16 years & $\begin{array}{l}\text { Students } \\
(\varnothing \text { age } 22)\end{array}$ & $\begin{array}{l}\text { Professionals } \\
(\varnothing \text { age } 32)\end{array}$ & $\begin{array}{l}\text { Retired persons } \\
(\varnothing \text { age } 68)\end{array}$ \\
\hline \multicolumn{7}{|c|}{ [a] Transfer $x(N)$ - maximum: 10 for all treatments } \\
\hline $2 €$ & $2.00(45)$ & $3.91(22)$ & $5.72(18)$ & $6.55(19)$ & & \\
\hline $5 €$ & & $3.44(39)$ & $5.31(32)$ & $6.57(59)$ & $6.58(31)$ & $5.38(34)$ \\
\hline $8 €$ & & & & $6.55(32)$ & & \\
\hline Aggregated & $2.00(45)$ & $3.61(61)$ & $5.46(50)$ & $6.56(110)$ & $6.58(31)$ & $5.38(34)$ \\
\hline Overall & & & & & & $5.11(331)$ \\
\hline \multicolumn{7}{|l|}{ [b] Return $y$} \\
\hline $2 €$ & 0.66 & 2.76 & 5.11 & 8.50 & & \\
\hline $5 €$ & & 1.64 & 5.19 & 7.42 & 9.03 & 8.65 \\
\hline $8 €$ & & & & 5.52 & & \\
\hline Aggregated & 0.66 & 2.04 & 5.16 & 7.05 & 9.03 & 8.65 \\
\hline Overall & & & & & & 5.37 \\
\hline \multicolumn{7}{|c|}{ [c] Rel. return $y / 3 x$} \\
\hline $2 €$ & 0.10 & 0.16 & 0.29 & 0.36 & & \\
\hline $5 €$ & & 0.15 & 0.34 & 0.33 & 0.39 & 0.57 \\
\hline $8 €$ & & & & 0.25 & & \\
\hline Aggregated & 0.10 & 0.15 & 0.32 & 0.31 & 0.39 & 0.57 \\
\hline Overall & & & & & & 0.29 \\
\hline \multicolumn{7}{|c|}{ [d] Profits (trustor/trustee) } \\
\hline $2 €$ & $8.64 / 5.36$ & $8.23 / 9.59$ & $9.39 / 12.06$ & $11.95 / 11.16$ & & \\
\hline $5 €$ & & $8.21 / 8.67$ & $9.88 / 10.75$ & $10.85 / 12.29$ & $12.16 / 11.00$ & $13.26 / 7.50$ \\
\hline $8 €$ & & & & $8.97 / 14.13$ & & \\
\hline Aggregated & $8.64 / 5.36$ & $8.22 / 9.00$ & $9.70 / 11.22$ & $10.49 / 12.63$ & $12.16 / 11.00$ & $13.26 / 7.50$ \\
\hline Overall & & & & & & $10.14 / 10.08$ \\
\hline
\end{tabular}


Our results do not show any sign of a relative endowment effect, regardless whether we compare transfers $x$, returns $y$, and relative returns $y / 3 x$ of different age groups at a given endowment level or with rising absolute endowment with age. For instance, we can apply a Jonckheere-test to check for a significant increase of transfers with age in three different ways: for transfers with $2 €$-endowments $(p<0.001)$, transfer with $5 €$-endowments $(p<$ 0.001), and, finally, when we try to account for the effects of relative stakes and compare 12 year olds with $2 €, 16$ year olds with $5 €$, and students with $8 €(p<0.01){ }^{26}$

Of course, we could not gather data for all possible endowment combinations, but the results in Table A.1 provide solid evidence that our results are not driven by a relative endowment effect.

${ }^{26}$ Additional support with respect to controlling for relative stakes is provided by the fact that transfers of 8 year olds with $2 €$ as endowment are significantly smaller than those of 12 year olds with $5 €$ (Mann Whitney Utest, $p<0.05)$. 


\section{Appendix B - Experimental instructions (originally in German)}

\section{Instructions}

During this experiment we ask you and the other participants to make decisions. As participant, you can earn real money, which will be paid to you privately in cash after the experiment. We will now read the instructions together. If you have any questions, please raise your hand and an experimenter will come to your place and will answer your questions privately (this means in a low voice).

\section{Procedure}

In this game, there are two roles: John/Joanna and Michelle/Michael. All pupils in this class are in the role of John/Joanna (in a second class or group it ran "role of Michelle/Michael") Members of another class will be in the role of Michelle/Michael (John/Joanna). Each John/Joanna will be anonymously paired with a Michelle/Michael for the experiment.

At the beginning of the experiment, John/Joanna receives an endowment of 10 units of money. John/Joanna has to decide how much of this amount to transfer to Michelle/Michael. Any amount between and including 0 and 10 units is feasible.

We will then triple the amount which John/Joanna decided to transfer to an anonymously paired Michelle/Michael. This means Michelle/Michael receives three times the amount that John/Joanna has sent.

Then Michelle/Michael has to make a decision. She/he receives three times the amount of units John/Joanna has sent. Now Michelle/Michael has to decide how much of this amount she/he would like to send back to John/Joanna. Please note: The amount that is sent back by Michelle/Michael to John/Joanna will not be tripled. That means that John/Joanna will receive exactly the amount Michelle/Michael sent back to him/her.

\section{Profits:}

John/Joanna will receive the amount kept for him-/herself, plus the amount of units that has been sent back by Michelle/Michael.

Michelle/Michael will earn the tripled amount that John/Joanna has sent minus the amount which has been sent back to John/Joanna.

Each unit of money is worth $0.5 €$ (or $0.2 €$ and $0.8 €$, respectively). 


\section{Decision making sheet (5€ endowment)}

\section{John/Joanna has to complete this part of the form:}

Endowment of John/Joanna: 10 units of money (worth $5 €$ )

I transfer the following amount of units to Michelle/Michael: (please mark)
O 0 units
O 1 unit
O 2 units
O 3 units
O 4 units
O 5 units
O 6 units
O 7 units
O 8 units
O 9 units
O 10 units

\section{Michelle/Michael has to complete this part of the form:}

I have received the following amount of units from John/Joanna (see above): units

Three times the above amount is the following amount: units

I transfer the following amount to John/Joanna (please mark - crossed values are not feasible)
O 0 units
O 1 unit
O 2 units
O 3 units
O 4 units
O 5 units
O 6 units
O 7 units
O 8 units
O 9 units
O 10 units
O 11 units
O 12 units
O 13 units
O 14 units
O 15 units
O 16 units
O 17 units
O 18 units
O 19 units
O 20 units
O 21 units
O 22 units
O 23 units
O 24 units
O 25 units
O 26 units
O 27 units
O 28 units
O 29 units
O 30 units 


\section{Appendix C - Raw data}

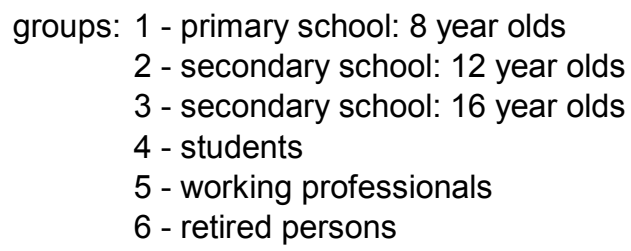

value: trustor's endowment in euro $\mathrm{x}$ : transfer of trustor $y: \quad$ return of trustee age $A$ : age of trustor age $B$ : age of trustee

\begin{tabular}{|c|c|c|c|c|c|}
\hline group & value & $\mathbf{x}$ & $y$ & age $A$ & age $B$ \\
\hline 1 & 2 & 0 & 0 & 8 & 8 \\
\hline 1 & 2 & 0 & 0 & 8 & 7 \\
\hline 1 & 2 & 0 & 0 & 8 & 8 \\
\hline 1 & 2 & 0 & 0 & 7 & 8 \\
\hline 1 & 2 & 0 & 0 & 7 & 8 \\
\hline 1 & 2 & 1 & 0 & 8 & 8 \\
\hline 1 & 2 & 1 & 0 & 7 & 8 \\
\hline 1 & 2 & 1 & 0 & 7 & 8 \\
\hline 1 & 2 & 1 & 1 & 8 & 8 \\
\hline 1 & 2 & 1 & 0 & 8 & 7 \\
\hline 1 & 2 & 1 & 2 & 8 & 7 \\
\hline 1 & 2 & 1 & 1 & 8 & 7 \\
\hline 1 & 2 & 1 & 1 & 8 & 8 \\
\hline 1 & 2 & 1 & 0 & 8 & 8 \\
\hline 1 & 2 & 1 & 1 & 7 & 8 \\
\hline 1 & 2 & 1 & 0 & 7 & 8 \\
\hline 1 & 2 & 1 & 0 & 8 & 8 \\
\hline 1 & 2 & 1 & 0 & 8 & 8 \\
\hline 1 & 2 & 1 & 0 & 8 & 8 \\
\hline 1 & 2 & 1 & 1 & 8 & 8 \\
\hline 1 & 2 & 2 & 1 & 7 & 8 \\
\hline 1 & 2 & 2 & 0 & 8 & 8 \\
\hline 1 & 2 & 2 & 0 & 8 & 7 \\
\hline 1 & 2 & 2 & 3 & 8 & 8 \\
\hline 1 & 2 & 2 & 1 & 8 & 8 \\
\hline 1 & 2 & 2 & 0 & 7 & 8 \\
\hline 1 & 2 & 2 & 0 & 7 & 8 \\
\hline 1 & 2 & 2 & 0 & 7 & 8 \\
\hline 1 & 2 & 2 & 0 & 8 & 8 \\
\hline 1 & 2 & 2 & 0 & 8 & 8 \\
\hline 1 & 2 & 2 & 2 & 8 & 8 \\
\hline 1 & 2 & 2 & 1 & 8 & 8 \\
\hline 1 & 2 & 3 & 1 & 8 & 8 \\
\hline 1 & 2 & 3 & 0 & 8 & 7 \\
\hline 1 & 2 & 3 & 0 & 8 & 8 \\
\hline 1 & 2 & 3 & 0 & 8 & 8 \\
\hline 1 & 2 & 3 & 1 & 8 & 8 \\
\hline 1 & 2 & 3 & 0 & 7 & 8 \\
\hline 1 & 2 & 3 & 0 & 8 & 7 \\
\hline 1 & 2 & 3 & 0 & 8 & 7 \\
\hline 1 & 2 & 4 & 0 & 7 & 7 \\
\hline 1 & 2 & 4 & 2 & 8 & 8 \\
\hline 1 & 2 & 4 & 1 & 8 & 7 \\
\hline 1 & 2 & 5 & 1 & 7 & 7 \\
\hline 1 & 2 & 10 & 8 & 8 & 8 \\
\hline 2 & 2 & 0 & 0 & 12 & 12 \\
\hline 2 & 2 & 0 & 0 & 12 & 12 \\
\hline 2 & 2 & 0 & 0 & 12 & 12 \\
\hline 2 & 2 & 0 & 0 & 12 & 12 \\
\hline 2 & 2 & 0 & 0 & 12 & 12 \\
\hline 2 & 2 & 1 & 0 & 12 & 12 \\
\hline
\end{tabular}

\begin{tabular}{|c|c|c|c|c|c|}
\hline group & value & $\mathbf{x}$ & $y$ & age $A$ & age $B$ \\
\hline 2 & 2 & 2 & 0 & 12 & 12 \\
\hline 2 & 2 & 2 & 0 & 12 & 12 \\
\hline 2 & 2 & 5 & 5 & 11 & 1 \\
\hline 2 & 2 & 5 & 2 & 12 & 1 \\
\hline 2 & 2 & 5 & 0 & 12 & 1 \\
\hline 2 & 2 & 5 & 3 & 11 & 1 \\
\hline 2 & 2 & 5 & 1 & 11 & 1 \\
\hline 2 & 2 & 5 & 2 & 12 & 1 \\
\hline 2 & 2 & 5 & 5 & 12 & 1 \\
\hline 2 & 2 & 5 & 2 & 12 & 1 \\
\hline 2 & 2 & 6 & 5 & 12 & 1 \\
\hline 2 & 2 & 6 & 4 & 12 & 1 \\
\hline 2 & 2 & 7 & 5 & 12 & 1 \\
\hline 2 & 2 & 7 & 3 & 12 & 1 \\
\hline 2 & 2 & 7 & 4 & 12 & 1 \\
\hline 2 & 2 & 8 & 6 & 12 & 1 \\
\hline 2 & 5 & 0 & 0 & 11 & 1 \\
\hline 2 & 5 & 1 & 0 & 11 & 1 \\
\hline 2 & 5 & 1 & 1 & 12 & 1 \\
\hline 2 & 5 & 1 & 2 & 11 & 1 \\
\hline 2 & 5 & 2 & 0 & 12 & 1 \\
\hline 2 & 5 & 2 & 1 & 12 & 1 \\
\hline 2 & 5 & 2 & 1 & 12 & 1 \\
\hline 2 & 5 & 2 & 0 & 12 & 1 \\
\hline 2 & 5 & 2 & 0 & 12 & 1 \\
\hline 2 & 5 & 2 & 1 & 12 & 1 \\
\hline 2 & 5 & 2 & 0 & 12 & 1 \\
\hline 2 & 5 & 2 & 1 & 11 & 1 \\
\hline 2 & 5 & 2 & 0 & 12 & 1 \\
\hline 2 & 5 & 2 & 1 & 12 & 1 \\
\hline 2 & 5 & 2 & 2 & 12 & 1 \\
\hline 2 & 5 & 3 & 1 & 11 & 1 \\
\hline 2 & 5 & 3 & 1 & 12 & 1 \\
\hline 2 & 5 & 3 & 1 & 12 & 1 \\
\hline 2 & 5 & 3 & 0 & 12 & 1 \\
\hline 2 & 5 & 3 & 0 & 12 & 1 \\
\hline 2 & 5 & 3 & 0 & 12 & 1 \\
\hline 2 & 5 & 4 & 1 & 12 & 1 \\
\hline 2 & 5 & 4 & 2 & 12 & 1 \\
\hline 2 & 5 & 4 & 4 & 11 & 1 \\
\hline 2 & 5 & 4 & 3 & 12 & \\
\hline 2 & 5 & 4 & 1 & 12 & \\
\hline 2 & 5 & 4 & 6 & 12 & 1 \\
\hline 2 & 5 & 5 & 0 & 12 & 1 \\
\hline 2 & 5 & 5 & 3 & 12 & 1 \\
\hline 2 & 5 & 5 & 1 & 12 & 1 \\
\hline 2 & 5 & 5 & 4 & 12 & 1 \\
\hline 2 & 5 & 5 & 2 & 11 & 1 \\
\hline 2 & 5 & 5 & 2 & 12 & \\
\hline 2 & 5 & 5 & 0 & 12 & 1 \\
\hline 2 & 5 & 5 & 0 & 12 & \\
\hline
\end{tabular}




\section{Appendix C - Raw data (contd.)}

\begin{tabular}{|c|c|c|c|c|c|c|c|c|c|c|c|}
\hline group & value & $x$ & $y$ & age $A$ & age $B$ & group & value & $\mathbf{x}$ & y ag & age $A$ & age $B$ \\
\hline 2 & 5 & $\hat{5}$ & 0 & 12 & 12 & 4 & 2 & 2.5 & 2.5 & 24 & 20 \\
\hline 2 & 5 & 6 & 6 & 12 & 12 & 4 & 2 & 4 & 4 & 19 & 20 \\
\hline 2 & 5 & 6 & 6 & 12 & 12 & 4 & 2 & 5 & 7.5 & 21 & 21 \\
\hline 2 & 5 & 10 & 10 & 12 & 12 & 4 & 2 & 5 & 5 & 20 & 24 \\
\hline 3 & 2 & 0 & 0 & 16 & 16 & 4 & 2 & 7 & 1 & 26 & 25 \\
\hline 3 & 2 & 2 & 2 & 16 & 16 & 4 & 2 & 7.5 & 11.5 & 20 & 22 \\
\hline 3 & 2 & 3 & 1 & 16 & 16 & 4 & 2 & 7.5 & 9.5 & 21 & 23 \\
\hline 3 & 2 & 4 & 0 & 16 & 16 & 4 & 2 & 7.5 & 10 & 21 & 20 \\
\hline 3 & 2 & 5 & 5 & 16 & 17 & 4 & 2 & 8.5 & 2.5 & 21 & 19 \\
\hline 3 & 2 & 5 & 7 & 16 & 16 & 4 & 2 & 10 & 30 & 21 & 21 \\
\hline 3 & 2 & 5 & 5 & 16 & 16 & 4 & 2 & 10 & 15 & 22 & 21 \\
\hline 3 & 2 & 5 & 1 & 16 & 16 & 4 & 2 & 10 & 20 & 22 & 21 \\
\hline 3 & 2 & 5 & 5 & 16 & 16 & 4 & 2 & 10 & 15 & 23 & 21 \\
\hline 3 & 2 & 5 & 5 & 16 & 16 & 4 & 2 & 10 & 15 & 20 & 20 \\
\hline 3 & 2 & 5 & 3 & 16 & 16 & 4 & 2 & 10 & 10 & 23 & 20 \\
\hline 3 & 2 & 5 & 3 & 15 & 16 & 4 & 5 & 0 & 0 & 21 & 23 \\
\hline 3 & 2 & 6 & 9 & 16 & 16 & 4 & 5 & 0.5 & 0 & 24 & 28 \\
\hline 3 & 2 & 9 & 14 & 16 & 16 & 4 & 5 & 0.5 & 1.5 & 22 & 21 \\
\hline 3 & 2 & 9 & 14 & 17 & 16 & 4 & 5 & 1 & 2 & 21 & 20 \\
\hline 3 & 2 & 10 & 0 & 15 & 16 & 4 & 5 & 1 & 1 & 23 & 22 \\
\hline 3 & 2 & 10 & 5 & 16 & 16 & 4 & 5 & 2 & 1 & 22 & 23 \\
\hline 3 & 2 & 10 & 13 & 16 & 16 & 4 & 5 & 2 & 0 & 26 & 21 \\
\hline 3 & 5 & 1 & 3 & 17 & 16 & 4 & 5 & 2.5 & 0.1 & 19 & 26 \\
\hline 3 & 5 & 2 & 0 & 16 & 16 & 4 & 5 & 2.5 & 0 & 22 & 29 \\
\hline 3 & 5 & 2 & 2 & 16 & 16 & 4 & 5 & 2.5 & 7.5 & 24 & 24 \\
\hline 3 & 5 & 3 & 1 & 16 & 16 & 4 & 5 & 3 & 4 & 20 & 19 \\
\hline 3 & 5 & 3 & 2 & 16 & 15 & 4 & 5 & 3 & 1 & 22 & 19 \\
\hline 3 & 5 & 3 & 2 & 16 & 16 & 4 & 5 & 3 & 2 & 20 & 21 \\
\hline 3 & 5 & 3 & 1 & 16 & 16 & 4 & 5 & 3 & 1 & 19 & 18 \\
\hline 3 & 5 & 3 & 2 & 16 & 16 & 4 & 5 & 3 & 0 & 27 & 21 \\
\hline 3 & 5 & 3 & 9 & 15 & 16 & 4 & 5 & 3.5 & 0 & 24 & 21 \\
\hline 3 & 5 & 3 & 2 & 16 & 16 & 4 & 5 & 4 & 3 & 27 & 21 \\
\hline 3 & 5 & 3 & 1 & 16 & 16 & 4 & 5 & 4 & 0 & 19 & 21 \\
\hline 3 & 5 & 3 & 5 & 16 & 16 & 4 & 5 & 4 & 2 & 21 & 27 \\
\hline 3 & 5 & 3 & 9 & 16 & 16 & 4 & 5 & 4 & 3 & 19 & 18 \\
\hline 3 & 5 & 4 & 1 & 16 & 16 & 4 & 5 & 5 & 6 & 20 & 19 \\
\hline 3 & 5 & 4 & 1 & 16 & 16 & 4 & 5 & 5 & 5 & 22 & 27 \\
\hline 3 & 5 & 5 & 3 & 16 & 16 & 4 & 5 & 5 & 0 & 35 & 20 \\
\hline 3 & 5 & 5 & 5 & 16 & 16 & 4 & 5 & 5 & 5 & 19 & 21 \\
\hline 3 & 5 & 5 & 5 & 16 & 16 & 4 & 5 & 5 & 5 & 19 & 23 \\
\hline 3 & 5 & 5 & 2 & 16 & 16 & 4 & 5 & 5 & 5 & 18 & 22 \\
\hline 3 & 5 & 6 & 6 & 16 & 16 & 4 & 5 & 5 & 0 & 19 & 21 \\
\hline 3 & 5 & 6 & 11 & 16 & 16 & 4 & 5 & 6 & 6 & 21 & 26 \\
\hline 3 & 5 & 6 & 7 & 16 & 16 & 4 & 5 & 7 & 7 & 19 & 22 \\
\hline 3 & 5 & 7 & 7 & 16 & 16 & 4 & 5 & 7.5 & 10 & 18 & 21 \\
\hline 3 & 5 & 7 & 0 & 16 & 16 & 4 & 5 & 7.5 & 0 & 18 & 22 \\
\hline 3 & 5 & 8 & 4 & 16 & 16 & 4 & 5 & 8 & 11 & 21 & 21 \\
\hline 3 & 5 & 8 & 10 & 16 & 16 & 4 & 5 & 8.5 & 10 & 24 & 19 \\
\hline 3 & 5 & 9 & 9 & 16 & 16 & 4 & 5 & 9 & 13 & 19 & 22 \\
\hline 3 & 5 & 10 & 17 & 16 & 16 & 4 & 5 & 10 & 10 & 20 & 21 \\
\hline 3 & 5 & 10 & 14 & 16 & 16 & 4 & 5 & 10 & 10 n.a. & & 23 \\
\hline 3 & 5 & 10 & 0 & 16 & 16 & 4 & 5 & 10 & 0 & 21 & 1 \\
\hline 3 & 5 & 10 & 15 & 16 & 16 & 4 & 5 & 10 & 0 & 29 & 2 \\
\hline 3 & 5 & 10 & 10 & 16 & 16 & 4 & 5 & 10 & 15 & 19 & 20 \\
\hline 4 & 2 & 2.5 & 0 & 21 & 20 & 4 & 5 & 10 & 12 & 20 & 30 \\
\hline 4 & 2 & 2.5 & 0 & 24 & 22 & 4 & 5 & 10 & 2 & 31 & 2 \\
\hline 4 & 2 & 2.5 & 2.5 & 20 & 24 & 4 & 5 & 10 & 15 & 22 & 28 \\
\hline 4 & 2 & 2.5 & 0.5 & 20 & 22 & 4 & 5 & 10 & 15 & 23 & 21 \\
\hline
\end{tabular}




\section{Appendix C - Raw data (contd.)}

\begin{tabular}{|c|c|c|c|c|c|}
\hline group & value & $\mathbf{x}$ & $y$ & age $A$ & age $B$ \\
\hline 4 & 5 & 10 & 14 & 26 & 19 \\
\hline 4 & 5 & 10 & 15 & 22 & 25 \\
\hline 4 & 5 & 10 & 15 & 22 & 21 \\
\hline 4 & 5 & 10 & 12.5 & 20 & 19 \\
\hline 4 & 5 & 10 & 20 & 20 & 24 \\
\hline 4 & 5 & 10 & 15 & 19 & 19 \\
\hline 4 & 5 & 10 & 30 & 21 & 18 \\
\hline 4 & 5 & 10 & 15 & 19 & 22 \\
\hline 4 & 5 & 10 & 15 & 25 & 21 \\
\hline 4 & 5 & 10 & 15 & 19 & 22 \\
\hline 4 & 5 & 10 & 15 & 18 & 20 \\
\hline 4 & 5 & 10 & 15 & 22 & 21 \\
\hline 4 & 5 & 10 & 10 & 19 & 18 \\
\hline 4 & 5 & 10 & 15 & 20 & 19 \\
\hline 4 & 5 & 10 & 15 & 25 & 19 \\
\hline 4 & 5 & 10 & 10 & 22 & 22 \\
\hline 4 & 8 & 0 & 0 & 20 & 21 \\
\hline 4 & 8 & 0 & 0 & 22 & 21 \\
\hline 4 & 8 & 0 & 0 & 21 & 20 \\
\hline 4 & 8 & 1 & 1 & 25 & 25 \\
\hline 4 & 8 & 1.5 & 0.5 & 27 & 24 \\
\hline 4 & 8 & 2.5 & \multicolumn{2}{|c|}{0 n.a. } & 22 \\
\hline 4 & 8 & 3 & 1 & 27 & 19 \\
\hline 4 & 8 & 3 & 0 & 24 & 23 \\
\hline 4 & 8 & 3 & 1 & 21 & 23 \\
\hline 4 & 8 & 4.5 & 4 & 20 & 22 \\
\hline 4 & 8 & 5 & 3 & 27 & 20 \\
\hline 4 & 8 & 5 & 0 & 20 & 21 \\
\hline 4 & 8 & 6 & 1 & 23 & 24 \\
\hline 4 & 8 & 7 & 7 & 19 & 27 \\
\hline 4 & 8 & 7 & 10 & 20 & 25 \\
\hline 4 & 8 & 7 & 8 & 19 & 22 \\
\hline 4 & 8 & 8 & 6 & 22 & 18 \\
\hline 4 & 8 & 8 & 11 & 25 & 31 \\
\hline 4 & 8 & 8 & 8 & \multicolumn{2}{|c|}{26 n.a. } \\
\hline 4 & 8 & 10 & 5 & 22 & 20 \\
\hline 4 & 8 & 10 & 10 & 21 & 24 \\
\hline 4 & 8 & 10 & 15 & 27 & 23 \\
\hline 4 & 8 & 10 & 15 & 23 & 21 \\
\hline 4 & 8 & 10 & 15 & 20 & 22 \\
\hline 4 & 8 & 10 & 0 & 19 & 19 \\
\hline 4 & 8 & 10 & 15 & 21 & 18 \\
\hline 4 & 8 & 10 & 10 & 23 & 23 \\
\hline 4 & 8 & 10 & 15 & 22 & 25 \\
\hline 4 & 8 & 10 & 0 & 24 & 22 \\
\hline 4 & 8 & 10 & 0 & 20 & 23 \\
\hline 4 & 8 & 10 & 15 & 21 & 21 \\
\hline 4 & 8 & 10 & 0 & 21 & 21 \\
\hline 5 & 5 & 0 & 0 & 22 & 33 \\
\hline 5 & 5 & 2 & 0 & 27 & 29 \\
\hline 5 & 5 & 2 & 2 & 27 & 26 \\
\hline 5 & 5 & 3 & 1 & 36 & 28 \\
\hline 5 & 5 & 3 & 0 & 30 & 32 \\
\hline 5 & 5 & 3 & 1 & 37 & 21 \\
\hline 5 & 5 & 4 & 1 & 32 & 32 \\
\hline 5 & 5 & 4 & 12 & 28 & 25 \\
\hline 5 & 5 & 5 & 1 & 24 & 27 \\
\hline 5 & 5 & 5 & 7 & 26 & 32 \\
\hline
\end{tabular}

\begin{tabular}{|c|c|c|c|c|c|}
\hline group & value & $\mathbf{x}$ & y ag & ge $A$ a & age $B$ \\
\hline 5 & 5 & 5 & 6 & 42 & 42 \\
\hline 5 & 5 & 5 & 5 n.a. & & 38 \\
\hline 5 & 5 & 6 & 8 & 31 & 30 \\
\hline 5 & 5 & 6 & 4 & 34 & 31 \\
\hline 5 & 5 & 6 & 6 n.a. & & 29 \\
\hline 5 & 5 & 6 & 6 n.a. & & 39 \\
\hline 5 & 5 & 7 & 11 & 49 & 30 \\
\hline 5 & 5 & 8 & 12 n.a. & & 26 \\
\hline 5 & 5 & 8 & 12 & 27 & 33 \\
\hline 5 & 5 & 8 & 8 & 50 & 26 \\
\hline 5 & 5 & 8 & 12 n.a. & & 28 \\
\hline 5 & 5 & 10 & 12 & 29 & 21 \\
\hline 5 & 5 & 10 & 15 & 36 & 28 \\
\hline 5 & 5 & 10 & 30 & 30 & 28 \\
\hline 5 & 5 & 10 & 15 & 32 & 25 \\
\hline 5 & 5 & 10 & 0 n.a. & & 29 \\
\hline 5 & 5 & 10 & 30 & 38 & 36 \\
\hline 5 & 5 & 10 & 16 n.a. & & 32 \\
\hline 5 & 5 & 10 & 6 & 40 & 25 \\
\hline 5 & 5 & 10 & 30 & 31 & 43 \\
\hline 5 & 5 & 10 & 2 & 25 & 28 \\
\hline 6 & 5 & 0 & 0 & $58 \mathrm{n} \cdot \mathrm{a}$ & \\
\hline 6 & 5 & 2 & 6 & 73 & 62 \\
\hline 6 & 5 & 2 & 4 & 60 & 77 \\
\hline 6 & 5 & 2 & 4 & 52 & 62 \\
\hline 6 & 5 & 3 & 4 & 58 & 59 \\
\hline 6 & 5 & 4 & 12 & 56 & 82 \\
\hline 6 & 5 & 4 & 12 & 55 & 70 \\
\hline 6 & 5 & 4 & 4 & 55 & 68 \\
\hline 6 & 5 & 4 & 6 & 66 & 77 \\
\hline 6 & 5 & 4 & 6 & 58 & 66 \\
\hline 6 & 5 & 4 & 4 & 80 & 81 \\
\hline 6 & 5 & 4 & 6 & 66 & 71 \\
\hline 6 & 5 & 4 & 4 & 67 & 72 \\
\hline 6 & 5 & 4 & 10 & 82 & 77 \\
\hline 6 & 5 & 5 & 15 & 57 & 70 \\
\hline 6 & 5 & 5 & 13 & 82 & 75 \\
\hline 6 & 5 & 5 & 4 & 66 & 69 \\
\hline 6 & 5 & 5 & 6 n.a. & & 66 \\
\hline 6 & 5 & 6 & 8 & 60 & 67 \\
\hline 6 & 5 & 6 & 3 & 60 & 62 \\
\hline 6 & 5 & 6 & 18 & 67 & 71 \\
\hline 6 & 5 & 6 & 9 & 50 & 77 \\
\hline 6 & 5 & 6 & 8 & 78 & 75 \\
\hline 6 & 5 & 6 & 8 & 80 & 75 \\
\hline 6 & 5 & 6 & 9 & 69 & 75 \\
\hline 6 & 5 & 6 & 12 & 70 & 82 \\
\hline 6 & 5 & 7 & 16 n.a. & & 60 \\
\hline 6 & 5 & 8 & 8 & 65 & 57 \\
\hline 6 & 5 & 8 & 12 & 68 & 58 \\
\hline 6 & 5 & 8 & 12 & 67 & 55 \\
\hline 6 & 5 & 9 & 12 & 69 & 78 \\
\hline 6 & 5 & 10 & 15 & 58 & 78 \\
\hline 6 & 5 & 10 & 2 & 62 & 71 \\
\hline 6 & 5 & 10 & 22 n.a. & & 70 \\
\hline
\end{tabular}

